\title{
A successful prediction?
}

London

TwELvE hours after last week's earthquake in northern California, the United States Geological Survey (USGS) claimed that it had "forecast" the event in a report issued last year.Californians may find the value of this forecast debatable, but the close resemblance between the earthquake and the event foretold, not just by USGS but by many US seismologists over the past decade, encourages confidence that a practical understanding of earthquakes on the San Andreas Fault is within reach.

The earthquake, estimated at magnitude 6.9 (with about one-fifteenth the energy of the great San Francisco earthquake of 1906), had its epicentre in the mountains north-east of Santa Cruz, and has been named 'Loma Prieta' after a lookout station there. Its depth is thought to be $18 \mathrm{~km}$, a little more than the characteristic $10-15 \mathrm{~km}$ depth of microearthquakes in the region.

So far, no unambiguous surface faulting has been identified, but very steep local terrain and thick brush makes it hard to distinguish true ruptures from superficial slumps and landslides. And from such a deep focus, the fault rupture may not have reached the surface at all.

The motion was primarily strike-slip (the two blocks of crust sliding past one another), typical of the San Andreas Fault but there was also a small thrust component (one block being forced over another). The total slip is estimated to have been about $50 \mathrm{~cm}$.

Since the main shock on Tuesday 17 October at 5:04 p.m. local time, thousands of aftershocks have spread out along the 50 $\mathrm{km}$ segment of the San Andreas Fault that rup-

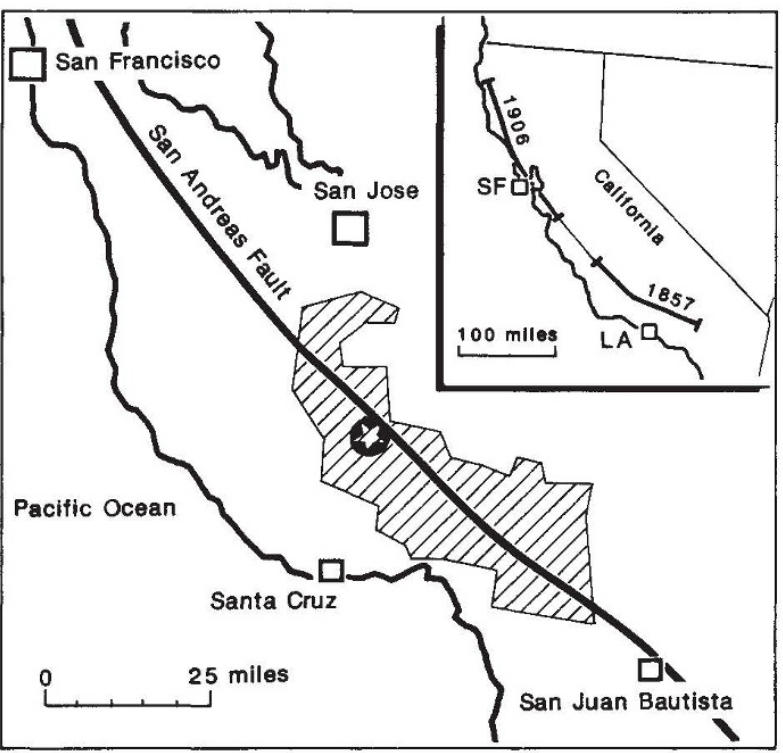

The San Francisco Peninsula segment of the San Andreas Fault (main map), showing the epicentre (star) and the region of densely clustered aftershocks (shading) marking the Loma Prieta rupture. Inset shows the segments of the fault that ruptured in the great earthquakes of 1906 and 1857 , separated by the 'central creeping segment'. SF, San Francisco; LA, Los Angeles. tured. This segment, running from Pajaro Gap in the south, near San Juan Bautista, to Lexington Reservoir in the north, is the southernmost part of the 1906 rupture, which extended north for $450 \mathrm{~km}$ towards Cape Mendocino.

The southern stretch has attracted the attention of seismologists since at least 1983, when Al Lindh, of USGS in Menlo Park, California, identified a $45-\mathrm{km}$ section north of San Juan Bautista as being likely to rupture in the following 20 years. For $150 \mathrm{~km}$ south of San Juan Bautista, the San Andreas Fault is creeping gradually, dissipating the strain that would cause an earthquake, but to the north and this 'central creeping segment', the fault is locked. The entire length of the 1906 rupture has been accumulating strain since 1906 , making a future earthquake more likely.

Simple models suggest that when the strain relieved by a previous earthquake has been re-accumulated, the fault is ripe for another event of the same magnitude. The slip in the 1906 earthquake varied from about 5 metres near San Francisco to near zero at San Juan Bautista. The southernmost $90 \mathrm{~km}$, the San Francisco Peninsula segment, slipped by only $1-3$ metres, and at a continuing slip rate of 16 mm per year will recover its 1906 slip before the rest of the northern San Andreas.

Such reasoning led USGS to assign a 20 per cent probability to a magnitude 7 earthquake happening on the Peninsula segment within 30 years of 1988 . But it put a probability of 30 per cent on an event rupturing only the southernmost $30 \mathrm{~km}$, the Santa Cruz Mountains segment, with a predicted magnitude of 6.5 . The Loma

Prieta event falls between these two predictions.

Some think that USGS was too conservative. Chris Scholz, of the LamontDoherty Geological Observatory in New York, estimated in 1985 that a $75-\mathrm{km}$ length of the segment had slipped only $1-$ 1.4 metres in 1906 , rather than the 2.5 metres assumed by USGS, leading to an earthquake recurrence time of only $60-90$ years, instead of 160 years. But despite all this uncertainty, there are reasons to think that earthquake prediction is getting better.

Most of the uncertainty in current predictions for the northern San Andreas derives from ignorance of what actually happened in 1906: estimates of the slip that occurred then vary by a factor of two. But modern geodetic instruments will give much more precise estimates of the slip that occurred last week. Moreover, the Loma Prieta event gives broad support to the idea that, at least on the San Andreas Fault, it is possible to identify "characteristic earthquakes' - recurring ruptures of identifiable segments, with magnitudes and recurrence intervals that are, in principle, predictable.

The next important test of this hypothesis will be in the Parkfield segment, a $30-\mathrm{km}$ section between the central creeping segment and the locked southern half of the fault. The Parkfield segment has experienced five moderate (magnitude 6) earthquakes since 1881, with an average recurrence time of 22 years. The most recent was in 1966, leading USGS to suggest a 90 per cent probability for a magnitude 6 earthquake on this segment in the next 30 years.

The Parkfield segment is being monitored for any precursory activity that might lead to a more specific prediction.In retrospect, there were seismic precursors to the Loma Prieta earthquake, in the form of two magnitude 5 earthquakes in June 1988 and August 1989. In each case, USGS issued a short-term (five-day) warning of enhanced probability of a larger earthquake, after which the probability reverted to its long-term value.

Similarly, there was a chance that the Loma Prieta earthquake itself could have triggered an earthquake on an adjacent segment of the San Andreas, but this threat has now receded. The largest aftershock recorded so far was of magnitude 5.2, 37 minutes after the main shock.

And what about the next one? Loma Prieta does not change the long-term probabilities for the region: there is still a probability of 50 per cent for a magnitude 7 earthquake in the Bay area over the next 30 years, and a 60 per cent probability for a magnitude $7.5-8$ shock on the southern San Andreas over the same period.

But according to Scholz, the Loma Prieta rupture may have stopped $25 \mathrm{~km}$ short of the northern end of the region of reduced slip in 1906. An earthquake rupturing this remaining length of fault would be only of magnitude 6 , but it would be much closer to the heavily populated Silicon Valley.

Laura Ganwin

\section{Earthquake magnitudes}

As earthquake sizes vary enormously, it is convenient to use a logarithmic scale. The well-known Richter magnitude is defined as the base-ten logarithm of the maximum seismicwave amplitude in micrometres, recorded on a standard seismograph at $100 \mathrm{~km}$ from the earthquake epicentre. An increase in magnitude of one unit corresponds to a factor of $\mathbf{1 0}$ increase in wave amplitude, but a factor of $\mathbf{3 0}$ increase in earthquake energy. 